Article

\title{
The Formation Mechanism and Model of the Surface Nanoscale Kirkendall Effect on Au Catalyst Island/GaAs Substrate by Thermal Vapor-Liquid-Solid Method with Two-Step Temperature Mode
}

\author{
Khac An DAO ${ }^{1,2, *}$, Hong Trang Pham ${ }^{3}{ }^{-}$, Tien Thanh Nguyen ${ }^{2}$ and Anh Tuan Phan ${ }^{2,4}$ \\ 1 Institute of Theoretical and Applied Research (ITAR), Duy Tan University, Trang An Complex, \\ Cau Giay district, Ha Noi 100000, Vietnam \\ 2 Institute of Materials Science (IMS), Vietnam Academy of Science and Technology (VAST), \\ 18 Hoang Quoc Viet Road, Cau Giay district, Ha Noi 100000, Vietnam; tienthanh938@gmail.com (T.T.N.); \\ tuanpa.ims@gmail.com (A.T.P.) \\ 3 Co-Worker at EMD Lab, Institute of Materials Science, Vietnam Academy of Science and Technology (VAST), \\ 18 Hoang Quoc Viet Road, Cau Giay district, Ha Noi 100000, Vietnam; trangpham8405@gmail.com \\ 4 Recently Working at Yokkaichi Operations (TMC), 800 Yamanoisshiki-Cho, Yokkaichi, \\ Mie Prefecture 512-8550, Japan \\ * Correspondence: andaokhac@gmail.com; Tel.: +84-912094015
}

Received: 30 September 2019; Accepted: 12 December 2019; Published: 16 December 2019

\begin{abstract}
The Surface Nanoscale Kirkendall Effect is an important part of the Kirkendall effect, and has special role in the formation of surface nano material configurations. It can also cause faults in interconnection contact systems, yet this kind of effect has not yet been identified and studied in detail. Based on the obtained experimental results, this paper proposes a formation mechanism and model of the mixed-surface nanoscale Kirkendall effect formed by the role of Au metal catalyst islands/strips on a GaAs surface using the thermal Vapor-Liquid-Solid method. The diffusion of $\mathrm{Ga}, \mathrm{As}, \mathrm{O}$ atoms and the absorption of $\mathrm{O}$ atoms from a low-vacuum ambient into Au droplets forming surface nanoscale $\mathrm{Au} / \mathrm{Ga} / \mathrm{O}$ clusters leaves behind vacancies and voids; this process results in the nanoscale Kirkendall effect. In addition, the outward diffusion of the surface nanoscale $\mathrm{Au} / \mathrm{Ga} / \mathrm{O}$ clusters leaving behind bare GaAs holes in place of the former $\mathrm{Au}$ island forms the surface Kirkendall effect. Consequently, the combination of the two mentioned effects forms a new kind of KE, the so-called Surface Nanoscale Kirkendall Effect. This effect is generated either partly or completely, depending on the technological conditions. Accompanying this effect, the different configurations of nanomaterials have grown in number. The outward diffusion of surface nanoscale $\mathrm{Au} / \mathrm{Ga} / \mathrm{O}$ clusters was caused by the concentration of surface cluster gradients, the weakening of chemical bonds due to the accumulation of vacancies, the porosity, and pit-etching beneath the $\mathrm{Au}$ island. The diffusivity of surface $\mathrm{Au} / \mathrm{Ga} / \mathrm{O}$ clusters is numerically estimated. Its values vary from $2 \times 10^{-10}$ to $10^{-11} \mathrm{~m}^{2} / \mathrm{s}$. Potential applications of the surface nanoscale Kirkendall effect, making use of its advantages, limitations and disadvantages, are also discussed and proposed.
\end{abstract}

Keywords: surface nanoscale Kirkendall effect; surface nanoscale $\mathrm{Au} / \mathrm{Ga} / \mathrm{O}$ clusters diffusion; $\mathrm{GaAs}$; directional nanomaterials growth; nanostructured catalysts; phase transfer catalysis 


\section{Introduction}

It is known that the Kirkendall Effect (KE) is the result of the different diffusivities of atoms in bulk diffusions, which causes the supersaturation of lattice vacancies; this effect has many important applications [1,2]. Recently, the Nanoscale Kirkendall Effect (NKE) has been the subject of intensive study, aiming to control the shapes and sizes of fabrication and formation of hollow structural nanomaterials such as nanotubes and hollow nanospheres [3-6]. The NKE could be the basic fabrication method for a varied range of hollow nanostructures; unfortunately, there is still relatively little theoretical work studying NKE. This is partly due to the complexity of the reaction system [4,5]. The Surface Nanoscale Kirkendall effect (SNKE) outlined here is a phenomenon caused by the diffusion fluxes of $\mathrm{Ga}$ and As atoms into Au droplets inside the Au catalyst island, forming Surface Nanoscale $\mathrm{Au} / \mathrm{Ga} / \mathrm{O}$ Clusters (SNCs). Balancing this process, the lattice vacancy flux was generated, forming Kirkendall voids just the beneath the Au catalyst island, thus creating a kind of NKE on the corresponding nanoscale subjects. Subsequently, the SNCs diffuse outwards, completely leaving behind the bare GaAs hole to form another kind of Surface Kirkendall Effect (SKE). Consequently, the combination of these two processes with the two different kinds of effects created a mixed Kirkendall Effect, the so-called SNKE. In this case, the formation of the SNKE is very complex; in principle, its formation mechanism is essentially to the same as the KE and NKE reported in the literature [1-5]. The SNKE is an important part of the KE family, possessing both the corresponding advantages and disadvantages, as well as the applications. Unfortunately, to date, there have been few works dealing with this kind of SNKE in detail. In our previously published works, we outlined several problems related to the formation of $\mathrm{Au}$ droplets, such as the growth process of nanowires using the Vapor-Liquid-Solid (VLS) method [7] with Au metal catalyst layer, but setting up a model of SNKE and discussing its formation mechanism has not been carried out in detail [8,9]. The formation style of this SNKE is complex and considerably different from that of NKE producing hollow nanotubes and hollow spheres [3-6,10,11].

The aim of this work is to discuss the formation mechanism and set up a draft model of SNKE formed by the role of Au catalyst islands/strips on a GaAs substrate during the thermal VLS method with a two-step temperature profile. Due to the vital importance of the role of Au metal catalysis in the kinetics of catalytic reactions, as well as the formation of nanoscale objects due to phase transfer catalysis (Au droplets, diffusion of $\mathrm{Au}, \mathrm{Ga}$, and $\mathrm{As}$, and absorption of $\mathrm{O}$ atoms to form $\mathrm{SNCs}$, Kirkendall voids, etc.), SNKE is consequently formed. Concretely, in the first thermal annealing step at temperature $\mathrm{T}_{1}$ for $\mathrm{Au} / \mathrm{GaAs}$ decomposition, the Au droplets will form with different sizes depending on the thickness of the $\mathrm{Au}$ island, and in the second thermal annealing step (so called the growing-diffusion step) at temperature $\mathrm{T}_{2}$ around the (lower or upper) $\mathrm{Au} / \mathrm{GaAs}$ Eutectic temperature $\left(630^{\circ} \mathrm{C}\right)$, the $\mathrm{Ga}$ and As atoms rapidly diffuse into the liquid-solid Au droplets, forming SNCs inside the Au catalyst island; these SNCs diffuse outwards, leaving behind a bare GaAs hole, resulting in the mixed SNKE effect on the GaAs surface. By controlling the thickness of the Au catalyst islands/strips, the sizes of the $\mathrm{Au}$ droplets can be controlled, different sizes of SNCs in the range of about $30 \mathrm{~nm}$ to $100 \mathrm{~nm}$ can be formed, the outward diffusion rate of the SNCs can be varied, and it is consequently possible to control the formation grades of SNKE, while simultaneously controlling the different configurations of nanoparticles (NPs), nanowires (NWs) and nanorods (NRs) grown outside the Au catalyst islands/strips. The diffusion of $\mathrm{Au}, \mathrm{Ga}$, As atoms is discussed, and the outward diffusion of SNCs is experimentally shown and discussed. The diffusivities of the SNCs under different technological conditions is also numerically estimated for the first time using random walk theory. The advantages, disadvantages and applications of SNKE are also outlined.

\section{The Experimental Results}

Figure 1 shows the results of the formation of SNKE and SNCs on the S9 sample, where the SNCs diffused outwards, with a diffusion distance estimated on the basis of a measurement from the edge point of the Au catalyst island circumference, along the radius in the diffusion direction to the end point of the observable diffused range of the SNCs. Its value is about $\mathrm{L} \sim 900 \mu \mathrm{m}$ (Figure 1a). 
$\mathrm{Au}$ droplets and SNCs were formed inside the Au island (Figure 1b). The magnified SEM image of another SNC region inside the Au catalyst island is shown in Figure 1c. In this case, although the Au island thickness is very thick $(1000 \mathrm{~nm})$, the growing diffusion temperature $\left(\mathrm{T}_{2}=620^{\circ} \mathrm{C}\right)$ in the second step is lower than the Eutectic temperature $\left(630^{\circ} \mathrm{C}\right)$ of the $\mathrm{Au} / \mathrm{GaAs}$ system. The liquid-solid $\mathrm{Au} / \mathrm{Ga} / \mathrm{O}$ phase, especially the $\mathrm{Ga} / \mathrm{O}$ nucleations (NW seeds), are not yet fully formed here, so it is difficult to grow the nanowires [8,9]. Here, the NP configurations mainly formed and diffused in an outward direction from the edge of the Au catalyst island, along the radius direction of the circle formed by the $\mathrm{Au}$ catalyst island (Figure 1d). Their sizes are in the range of $50 \mathrm{~nm}$ to $200 \mathrm{~nm}$.
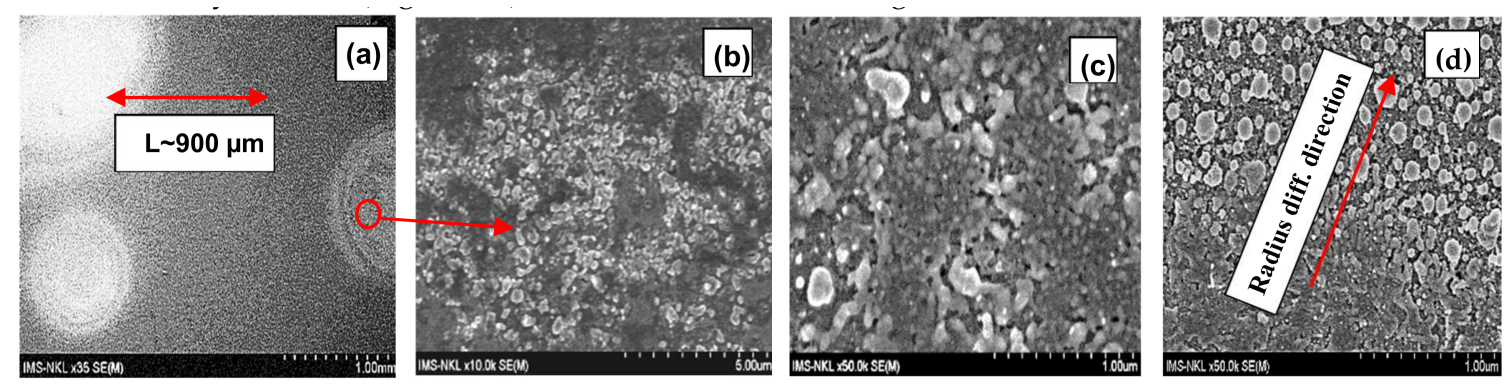

Figure 1. FESEM micrographs of $S 9$ sample with technological conditions: Au island thickness of $1000 \mathrm{~nm}$, thermal annealing at $\mathrm{T}_{1}=410^{\circ} \mathrm{C}$ for $20 \mathrm{~min}$, and at $\mathrm{T}_{2}=620^{\circ} \mathrm{C}$ for $30 \mathrm{~min}$ in the $10^{-1}-10^{-2}$ torr low vacuum closed tube. (a) the SNCs diffused outward from Au islands, (b) the Au droplets and SNCs formed inside the Au island, (c) the magnified SEM image of another SNC region inside the Au catalyst island, and (d) the NP configurations mainly formed and diffused outward along the radius direction.

Figure 2 shows the results of the formation of SNKE on the S10 sample with SNC diffusion lengths of up to about $\mathrm{L} \sim 1300 \mu \mathrm{m}$. Here, the SNKE is almost completely formed (Figure $2 \mathrm{~b}$ ). The NPs, NWs and NRs were grown together (Figure 2c,d) along the diffusion direction, with sizes of about $100 \mathrm{~nm}-200 \mathrm{~nm}$. Figure $2 \mathrm{~d}$ shows the magnified SEM image of another region outside the Au island (Figure S6). In this case, the Au island thickness is $1000 \mathrm{~nm}$, the GaAs decomposition temperature $\left(\mathrm{T}_{1}=440^{\circ} \mathrm{C}\right)$ is somewhat high, and the growing-diffusion temperature $\mathrm{T}_{2}=640{ }^{\circ} \mathrm{C}$, which is higher than the Eutectic temperature $\left(630^{\circ} \mathrm{C}\right)$ of the $\mathrm{Au} / \mathrm{GaAs}$ system. $\mathrm{Ga} / \mathrm{O}$ nucleations could be formed in order to promote the growth of nanomaterial morphologies. The grown NPs, NWs and NRs here have sizes of about $50 \mathrm{~nm}-150 \mathrm{~nm}$. In this case, the Au island thickness is thick. We suggest that the diffusion of $\mathrm{Ga}$ and As atoms into Au droplets that are large in size was not yet able to reach a fully supersaturated level; on the other hand, the growing-diffusion time $\left(t_{4}\right)$ was not so long, and it was consequently difficult for sharp nanomaterial configurations to form; the lengths of the NWs and NRs are also not so clearly defined (Figure $2 \mathrm{c}, \mathrm{d}$ ).
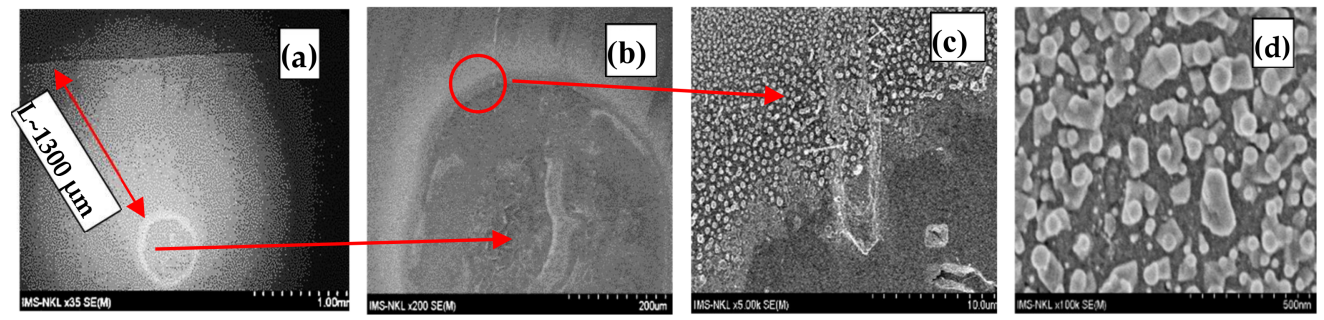

Figure 2. FESEM micrographs of S10 sample with technological conditions: Au island thickness of $1000 \mathrm{~nm}$, thermal annealing at $\mathrm{T}_{1}=440{ }^{\circ} \mathrm{C}$ for $20 \mathrm{~min}$, and after that at $\mathrm{T}_{2}=640{ }^{\circ} \mathrm{C}$ for $30 \mathrm{~min}$ in the $10^{-1}-10^{-2}$ torr low vacuum closed tube; (a) the outwards diffusion of SNCs from Au island; (b) the magnified image of Au island; (c) the magnified image of the region at the Au island circumference edge; (d) the magnified image of another region outside the Au island. 
Figure 3 shows the results of the complete formation of SNKE on the S7 sample where all SNCs diffused outwards from the Au catalyst island. Figure 3a,b shows the SEM images of a former corner of the $\mathrm{Au}$ island where all of the SNCs diffused outward, leaving behind a corner of bare GaAs holes. Figure $3 \mathrm{c}, \mathrm{d}, \mathrm{f}$ shows the different NW sizes decreasing along the outward diffusion direction. Figure 3e shows a magnified SEM image of a region in Figure 3d where the NWs had large nanospheres located on their tops. The Ga/O nucleations-NW seeds inside the SNCs-could be completely formed due to the suitable technological conditions, so during the outward movement, the nano seeds in the SNCs continued growing into configurations of NWs that were primarily horizontal, with weak bases, and with Au spheres located on the tops of the NWs. The NW diameter sizes were in a range from $30 \mathrm{~nm}$ to $100 \mathrm{~nm}$. Their sizes decrease along the outward diffusion direction. The growth mechanism of the NWs during the outward diffusion of the SNCs is, in this case, hard to clearly explain. Here, we suggest that the growth mechanism of the NWs could be explained by the modified VLS method, i.e., partly by the initial VLS mechanism [7] and/or by the Oxide Assisted Growth (OAG) Au catalyst-mediated VLS mechanism suggested by Y.F. Zheng and S. Noor Mohammad [12-14].
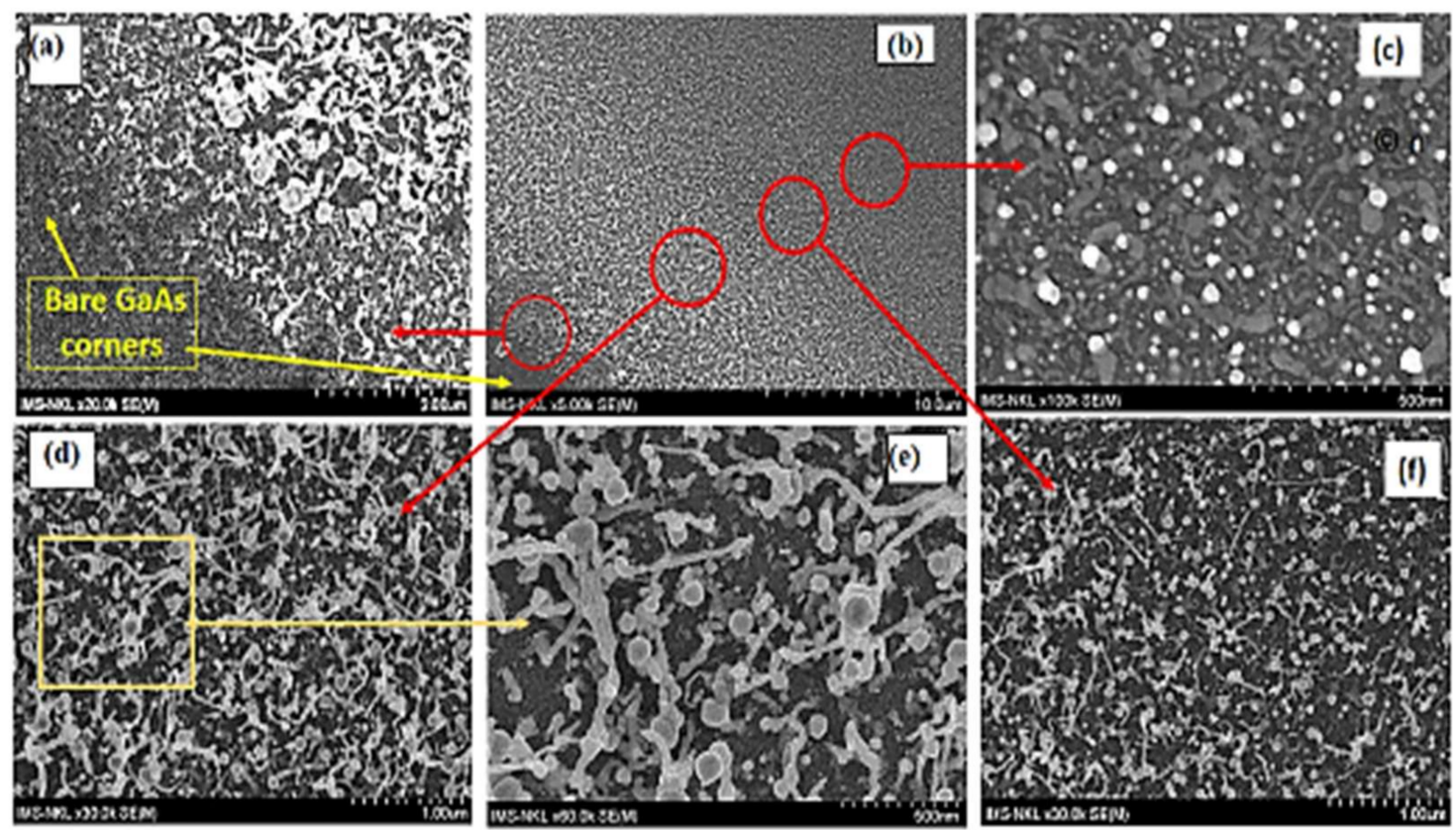

Figure 3. FESEM micrographs of the S7 sample with technological conditions: Au thickness of $70 \mathrm{~nm}$, thermal annealing at $\mathrm{T}_{1}=410^{\circ} \mathrm{C}$ for $20 \mathrm{~min}$, and at $\mathrm{T}_{2}=650{ }^{\circ} \mathrm{C}$ for $90 \mathrm{~min}$ in the $10^{-1}-10^{-2}$ torr low vacuum closed tube. $(\mathbf{a}, \mathbf{b})$ show the corners of bare GaAs holes where all of the SNCs diffused outward, $(\mathbf{c}, \mathbf{d}, \mathbf{f})$ show the different decreasing sizes of NW grown at different positions in (b) along the outward diffusion direction, and (e) shows a magnified SEM image of a region in (d) where the NWs had large nanospheres located on their tops.

Figure 4 shows another typical result of the completed formation of SNKE, with Kirkendall voids formed clearly around the Au metal catalyst island. The formation of Kirkendall voids is a result of the vacancy flux [1-5], which is the opposite of the diffusion flux of Ga and As atoms into Au droplets. Here, we can clearly see the entire bare GaAs hole formed in place of the former Au catalyst island located on the GaAs surface after all the SNCs have diffused outward, with Kirkendall voids forming around the circle formed by the bare GaAs hole (Figure 4a,b). The initial boundary of the edge of the $\mathrm{Au}$ island in this case moved outward by about $10 \mu \mathrm{m}$ (Figure $4 \mathrm{a}$ ), and the regular NWs grown along the radius diffusion direction simultaneously exhibited decreased sizes of about $100 \mathrm{~nm}$ to $50 \mathrm{~nm}$ (Figure 4c,d). 

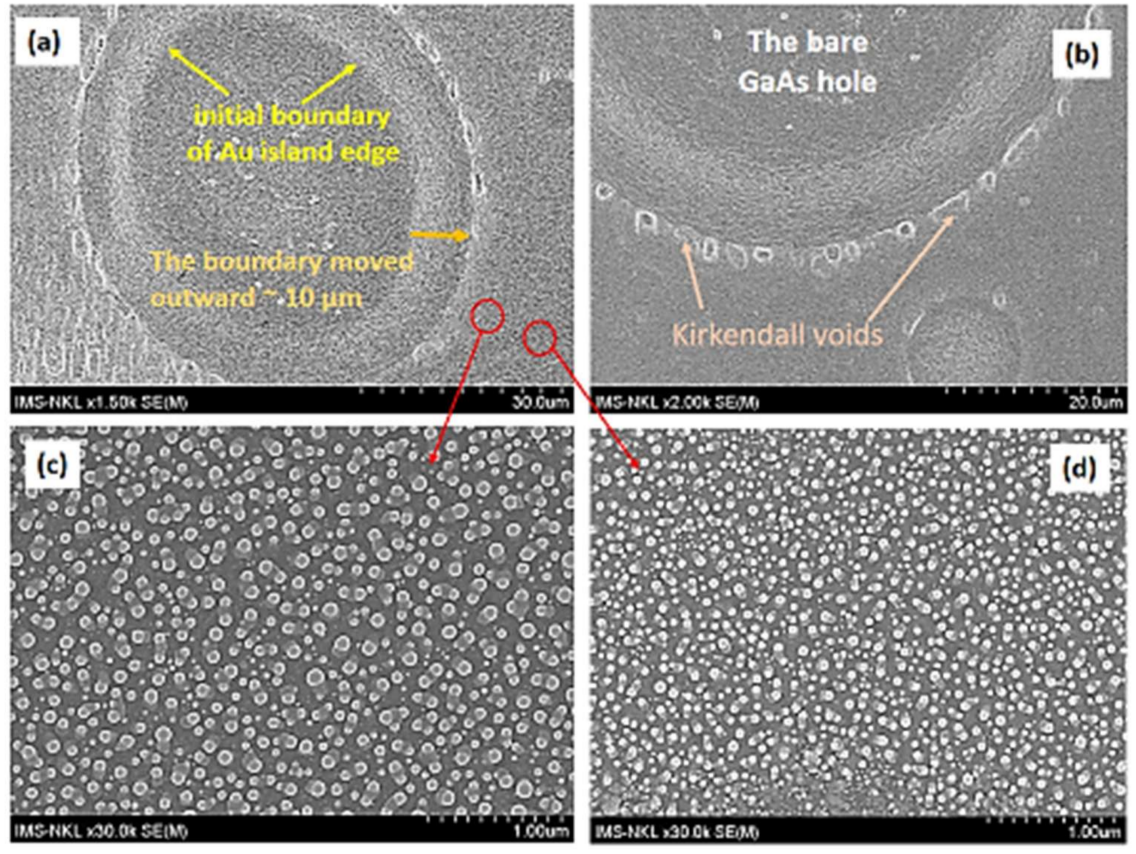

Figure 4. FESEM micrographs of S15 sample: the bare GaAs hole with the initial boundary moved outward and the formation of Kirkendall voids (a); the magnified image of a part of the bare GaAs hole (b); and the NWs grown with decreased size (c,d) under the following technological conditions: Au island thickness of $200 \mathrm{~nm}$, thermal annealing at $\mathrm{T}_{1}=410^{\circ} \mathrm{C}$ for $20 \mathrm{~min}$, and after that at $\mathrm{T}_{2}=650{ }^{\circ} \mathrm{C}$ for $30 \mathrm{~min}$ in the $10^{-1}-10^{-2}$ torr low vacuum closed tube.

In this case, the $\mathrm{Au}$ island thickness was $200 \mathrm{~nm}$, the decomposition temperature at the first step was $\mathrm{T}_{1}=410{ }^{\circ} \mathrm{C}$, and at the second step it was $\mathrm{T}_{2}=650{ }^{\circ} \mathrm{C}$, which is rather higher than the Eutectic temperature $\left(630^{\circ} \mathrm{C}\right)$. Here, the NWs have grown vertically with strong bases, and there are $\mathrm{Au}$ spheres (white in color) located on the tops of the NWs. This is evidence of the VLS mechanism, which predominates during the growth process [7-9]. The VLS growth mechanism could be explained here partly by the initial VLS mechanism [7] or by the Oxide Assisted Growth (OAG) Au catalyst-mediated VLS mechanism suggested by Y.F. Zheng [13] and S. Noor Mohammad [14]. The complete formation of SNKE left a bare circular GaAs hole on the surface in the place of the former Au catalyst island (Figure 4a,b).

The results of NW composition were investigated by Electron Diffraction X-ray (EDX), as shown in Figure 5. Based on the results data in Figure 5, we can see that the GaAs substrate composition in position 004 has $8.8 \% \mathrm{O}, 46.15 \% \mathrm{Ga}$, and $45.05 \%$ As. This measured data could be acceptable, because we assume that during the outwards diffusion of SNCs, some $\mathrm{Ga}$ and As atoms could diffuse from the GaAs surface into the moving SNCs; furthermore, $\mathrm{O}$ atoms are also absorbed into both the GaAs surface and the moving SNCs. In addition, the GaAs surface in this case is not an ideal pure GaAs surface. The structure compositions of the Au spheres located on the tops of the NWs (positions 001, $002,003,005,007)$ contain about $66.81 \%$ to $84.59 \% \mathrm{Au}$. The moderate differences in the measured Ga, As and $\mathrm{O}$ ratio data here can be explained by the different sizes of the formed SNCs containing different $\mathrm{Ga}$, As, $\mathrm{O}$ ratios, leading to the formation of different NWs sizes and atomic ratios. The composition of NW bodies in position 006 is $14.64 \% \mathrm{O}, 34.11 \% \mathrm{Ga}$, and $45.56 \%$ As, and in position 008 , it is $9.86 \%$ $\mathrm{O}, 40.42 \% \mathrm{Ga}$, and $40.77 \%$ As. These NW bodies are formed from different SNCs, so the sizes and composition ratios of the NWs could be different. It is worth noting that the As element is also shown in positions 006 and 008 of the NW bodies, which is attributed to the As composition of the GaAs substrate having an impact on the EDX measurement as a result of the NWs in these positions lying horizontally directly on the GaAs substrate. Several other elements are also shown, and these elements could have entered the GaAs sample during the chemical treatment and annealing process. 

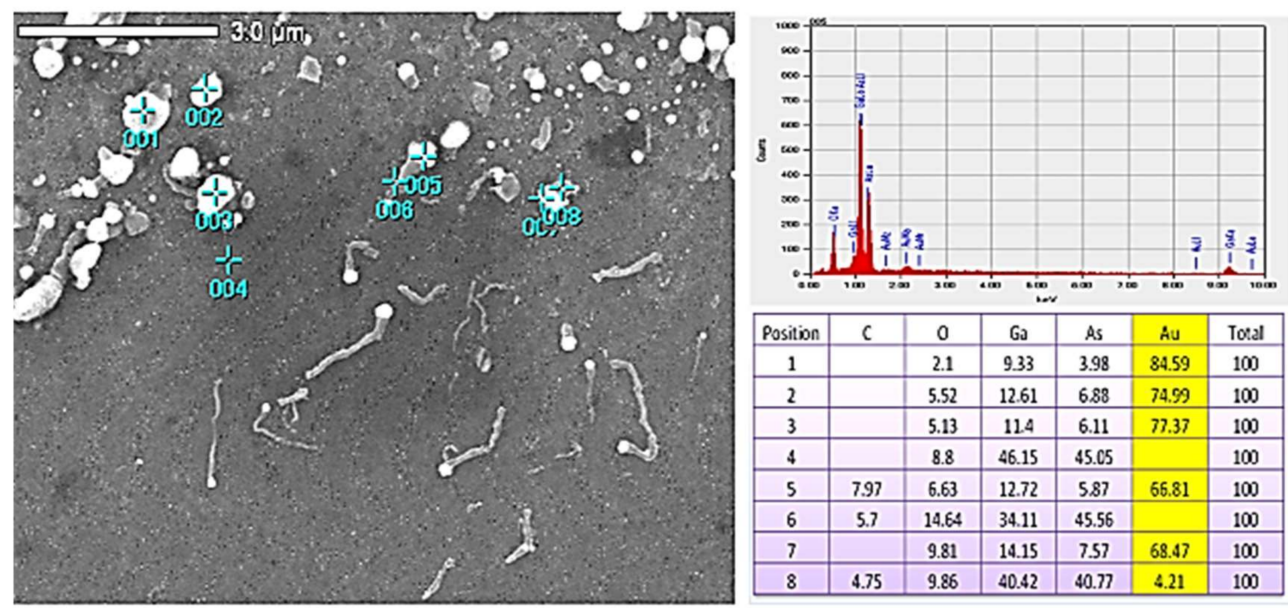

Figure 5. FESEM micrograph of the S7 sample showing the EDX measured positions, EDX spectrum measurement of the 005 position, and the EDX results of compositions of the NWs, of the Au spheres located on the tops of the NWs, and of the GaAs substrate.

\section{Discussion}

\subsection{On the Formation Mechanism of SNKE}

As is known, Kirkendall reported in 1942 what has more recently been called the Kirkendall effect (KE), explaining the interdiffusion between Copper and Zinc in a copper/brass system [1,2]. The discovery of the KE at that time is significant, because it validated the vacancy model for atomic diffusion. KE is also significant in explaining the failure of wire bonds due to void formation [10,11]. The subjects concerning KE in this case are large-scale bulk materials or thin film materials [11].

The formation of the Nanoscale Kirkendall effect (NKE) was first reported by Yin et al. in 2004 [10]. The authors observed the formation of hollow nanospheres while exploring the sulfidation of cobalt nanoparaticles by injecting a solution of sulfur into 1, 2-dichlorobenzene hot Co nanocrystals. Since this first report, the name of NKE has become very popular, and has been adopted by many research groups for the synthesis of hollow nanoparticles, covering a wide range of materials [11]. So the NKE formed on the nano subjects such as nano hollow spheres and hollow NWs. Unfortunately, to date, many problems have arisen with unclear solutions, e.g., it is unclear how KE manifests in bimetallic NPs and where the voids nucleate in NPs, because their sizes are usually too small to have grain boundaries [10,11]. These problems are difficult emerging research topics [11].

In addition, KE appears in bulk materials, and NKE appears in nanomaterials, as described in the above section. We are sure that there is a Surface Kirkendall Effect (SKE) branch belonging to the common KE family. The SKE could have different types with different formation mechanisms. In such an SKE branch, the Surface Kirkendall effect could appear on different subjects, for example:

- $\quad$ on the surface of the conventional bulk material (so-called SKE)

- $\quad$ on the surface of nanoscale subjects (or on the interface between two nanoscale subjects in the defined bulk material environment (so-called NSKE)

- $\quad$ on the surface of a mixed system including the surface of nanoscale subjects and on the bulk material (substrate) surface, as in our case (so-called SNKE).

Concerning the SNKE proposed in our case, especially with regard to the formation mechanism of this SNKE, we see here that the SNKE occurs in two main stages: In the first stage, the Au droplets form, and $\mathrm{Ga}$, As, and $\mathrm{O}$ atoms diffuse into the liquid-solid phase of Au droplets to form surface nanoscale $\mathrm{Au} / \mathrm{Ga} / \mathrm{O}$ clusters (SNCs), leaving behind vacancy voids just beneath the SNCs. Each SNC forms together with a small vacancy void (small Kirkendall void) just beneath each SNC (Figure S2). The Kirkendall void diffusion flux formation is balanced by the diffusion fluxes of the related atoms. 
This mixed nanosystem could be considered to be a "specific NKE". In the second stage, depending on the technological conditions, all SNCs will diffuse outwards completely from the Au island, leaving behind the bare GaAs hole in place of the former location of the Au catalyst island, forming the SKE. Consequently, the combination of the two mentioned effects, there will be a new kind of Kirkendall effect, as in our case: the so-called Surface Nanoscale Kirkendall Effect (SNKE).

The formation mechanism of SNKE could be explained concretely as the followings: depending on the technological conditions, including the Au metal catalyst island thickness, the temperature profile $\left(T_{1}\right.$ and $\left.T_{2}\right)$, and the thermal annealing times $\left(t_{2}\right.$ and $\left.t_{4}\right)$, the formation degree of SNKE can be controlled. In the first stage, during the annealing step at temperature $T_{1}$ for annealing time $t_{2}$, the $\mathrm{Au} / \mathrm{GaAs}$ is decomposed. The Au metal catalyst islands will be disturbed, forming Au droplets. The thicker the $\mathrm{Au}$ islands are, the bigger the Au droplets that will be formed [8,9]. During the decomposition of the GaAs substrate, the Ga and As atoms diffuse rapidly into the Au droplets, forming SNCs inside the Au metal catalyst islands. Unfortunately, As atoms are insoluble in Au droplets, and diffuse or evaporate outwards from the surface of the Au droplets. During the second growing-diffusion step at temperature $\mathrm{T}_{2}$ at or above the $\mathrm{Au} / \mathrm{GaAs}$ Eutectic temperature $\left(630{ }^{\circ} \mathrm{C}\right)$ for growing-diffusion time $\mathrm{t}_{4}$, the $\mathrm{Au} / \mathrm{Ga}$ liquid-solid phase will be formed. During this process, the diffusion of $\mathrm{Ga}$ and As atoms and the absorption of oxygen $(\mathrm{O})$ atoms will continue taking place, forming SNCs inside the Au island ([8,9] Figure S2). Balancing the Ga, As diffusion fluxes, vacancy accumulations will be generated, forming Kirkendall voids beneath the SNCs. All chemical-physical reaction processes occurring in this stage can be considered to be similar to those of NKE [10]. In the second stage, depending on the temperature profile, and especially on the sizes of the formed SNCs, these clusters will diffuse outwards from the Au island either partly (as in Figures 1 and 2) or completely (Figures 3 and 4 ) to form the SNKE. When the growing-diffusion time $\left(t_{4}\right)$ is further increased, all SNCs, including various nanomaterial configurations (NPs, NWs and NRs) inside and outside the Au island will continue to diffuse outwards further. In this case, the Kirkendall shift could also be formed by incorporating inert inclusions, so-called markers, at the interface (as in Figure 4a,b). So the formation mechanism of the SNKE is determined mainly by the role of the Au metal catalyst island causing different diffusion fluxes of $\mathrm{Au}, \mathrm{Ga}, \mathrm{As}, \mathrm{O}$ atoms, and of the SNCs outward diffusion flux.

Indeed, the formation of the SNKE could be more complex. The formation mechanism of SNKE here is considerably different from the formation mechanism of the KE in bulk alloy diffusion [1,2], and from that of NKE in the formation of nanotubes and hollow nanospheres described in the literature [3-6,10,11].

\subsection{The Role of Au Metal Catalyst Amount in the Phase Transfer Catalysis and Kinetics of Reactions for the Formation of SNKE}

As is known, Surface Diffusion (SD) and/or Surface Cluster Diffusion (SCD) is a basic phenomenon in which the surface atoms, molecules and/or surface clusters diffuse along the surface to assemble into desirable configurations [15]. In our case, both SD of elemental atoms (Au, Ga, As, O) and SCD (Au droplets, mixed SNCs) take place simultaneously in the process, so it is difficult to investigate these phenomena separately. Concerning the formation of SNKE, there are many physical-chemical kinetic processes and phase transfer catalysts taking place: in the first stage, the diffusion of Ga and As atoms into the $\mathrm{Au}$ droplets at temperatures $\mathrm{T}_{1}$ and $\mathrm{T}_{2}$ forms the SNCs. The reaction of GaAs with Au islands occurs via a dissociative diffusion process. Since As atoms are insoluble in gold, As atoms can pass easily through the gold lattice and evaporate from the free surface of the gold [16,17]. Some mixed transfer phases of $\mathrm{Au}_{\mathrm{x}} \mathrm{Ga}_{\mathrm{y}}$ could be formed, such as the $\alpha$-gold-rich solid solution, $\beta$-hexagonal $\mathrm{Au}_{2} \mathrm{Ga}_{2}$, orthorhombic $\mathrm{Au}_{2} \mathrm{Ga}$, or $\mathrm{Au}_{7} \mathrm{Ga}_{2}$ [16-19]. During thermal annealing at temperature $\mathrm{T}_{2}$ which is at or above the Eutectic temperature $\left(630^{\circ} \mathrm{C}\right)$, the liquid-solid phase of Au-GaAs was formed as a result of the chemical-physical interactions. At this time, both $\mathrm{Ga}$ and As atoms continued to diffuse into the liquid Au droplets, while simultaneously, the liquid Au droplets also absorbed oxygen $(\mathrm{O})$ atoms from the remaining ambient in the low vacuum closed tube. Consequently, the composition of 
the Au droplets changed to SNCs, with a certain level of supersaturation, and the Ga/O nucleations of the nano configuration seeds will also be formed depending on the level of supersaturation. In the second stage, the SNCs are located inside the Au island; these SNCs have considerable potential to diffuse outwards due to the concentration cluster gradient inducing a diffusing force around the circumference of the Au catalyst island. In addition, there is a weak chemical bond between the SNCs and the GaAs surface beneath the Au island due to porosity caused by the vacancy accumulations and pit etchings [9,16-19], which is also another of the main factors determining the outward diffusion of SNCs to form the SNKE.

Briefly, the diffusion of $\mathrm{Au}, \mathrm{Ga}$, as and $\mathrm{O}$ atoms and the outwards diffusion of SNCs play vitally important roles in the formation of the SNKE. To date, the diffusivities of Ga and As atoms and Au atoms in GaAs materials have been intensively studied, and their diffusivities have received different uncertain values in different works [20-27]. Here, we list the typical diffusivity data of $\mathrm{Au}, \mathrm{Ga}$ and As, as presented in the published literature, in Table 1, below. From the listed data, we can see that the Au diffusivities in the GaAs material and in the GaAs nanowire are very fast; the next is the diffusivity of Ga atoms, while the diffusivities of surface Au droplets and SNCs can almost not be found in the literature. There is only one work [28] dealing with the determination method of the surface diffusion coefficient, in which the author proposed new correlations for the activation energy $\left(E_{\text {diff }}\right)$ and pre-exponential factor $(D o)$ for thermally activated surface diffusion on metals, semiconductors, and some types of insulators.

Table 1. The list of the diffusivities of $\mathrm{Au}, \mathrm{Ga}$ and $\mathrm{As}$ atoms in $\mathrm{GaAs}$ material published in the literature.

\begin{tabular}{|c|c|c|c|c|c|}
\hline $\begin{array}{l}\text { Name of Element } \\
\text { Diffusion and/ or } \\
\text { Surface Clusters }\end{array}$ & $\begin{array}{l}\text { In Materials } \\
\text { (Substrate, } \\
\text { Samples, NW, } \\
\text { Symbols ... ) }\end{array}$ & $\begin{array}{l}\text { Diffusion } \\
\text { Temperature } \\
\left({ }^{\circ} \mathrm{C}\right)\end{array}$ & $\begin{array}{l}\text { Name of } \\
\text { Element } \\
\text { Diffusivity }\end{array}$ & $\begin{array}{c}\text { Published Data of Element } \\
\text { Diffusivity } \\
\left(\mathrm{m}^{2} / \mathrm{s} \text { or } \mathrm{cm}^{2} / \mathrm{s}\right)\end{array}$ & $\begin{array}{l}\text { Reference } \\
\text { (Calculated or } \\
\text { Estimated } \\
\text { Methods) }\end{array}$ \\
\hline Ga diffusion & GaAs & 640 & $\begin{array}{l}\text { Ga atom } \\
\text { diffusivity }\end{array}$ & $\begin{array}{c}D_{\mathrm{Ga}}(\mathrm{ni})=4 \times 10^{-25} \text { to } \\
10^{-20}\left(\mathrm{~cm}^{2} / \mathrm{sec}\right) \text { depending on } \\
\text { vacancies, interstitials }\end{array}$ & $\begin{array}{c}{[27]} \\
\text { U.Gösele at al. }\end{array}$ \\
\hline Ga diffusion & GaAs & $\begin{array}{c}795 \\
1230\end{array}$ & $\begin{array}{l}\text { Ga atom } \\
\text { diffusivity } \\
\left(D_{\mathrm{Ga}}\right)\end{array}$ & $\begin{array}{l}6.9 \times 10^{-19} \mathrm{~cm}^{2} / \mathrm{s} \\
3.3 \times 10^{-13} \mathrm{~cm}^{2} / \mathrm{s}\end{array}$ & $\begin{array}{l}\text { [24] } \\
\text { T.Y.Tan }\end{array}$ \\
\hline Ga diffusion & $\begin{array}{l}40 \mathrm{~nm} \\
\text { polycrystalline } \\
\text { Gold }\end{array}$ & 540 & $\begin{array}{l}\text { Ga atom } \\
\text { diffusivity }\end{array}$ & $1.2 \times 10^{-17} \mathrm{~m}^{2} \mathrm{~s}^{-1}$ & $\begin{array}{l}\text { [23] } \\
\text { Editor by } \\
\text { D.J. Fisher }\end{array}$ \\
\hline $\begin{array}{c}\text { Au } \\
\text { diffusion }\end{array}$ & $\begin{array}{l}\text { In the growing } \\
\text { GaAs nanowire }\end{array}$ & $725 \mathrm{~K}$ & $\begin{array}{l}\text { Au diffusivity } \\
\text { In } \mathrm{NW} \text { grown } \\
\text { from } \mathrm{Au} / \mathrm{GaAs}\end{array}$ & order of $10^{-4} \mathrm{~cm}^{2} / \mathrm{s}$ & $\begin{array}{c}{[20]} \\
\text { Bin Chen et. al. by } \\
\text { random walk } \\
\text { theory, } \\
D \sim L^{2} / \tau\end{array}$ \\
\hline $\begin{array}{c}\text { Au } \\
\text { diffusion }\end{array}$ & $\begin{array}{c}\text { GaN } \\
\text { in } 2 \mu \mathrm{m} \text { thick } \\
\text { undoped wurtzite }\end{array}$ & $\begin{array}{l}300 \\
400\end{array}$ & $\begin{array}{l}\text { Au atom } \\
\text { diffusivity }\end{array}$ & $\begin{array}{l}\mathrm{D}\left(300^{\circ} \mathrm{C}\right)=1.03 \times 10^{-15} \mathrm{~cm}^{2} / \mathrm{s} \\
\mathrm{D}\left(400^{\circ} \mathrm{C}\right)=1.69 \times 10^{-14} \mathrm{~cm}^{2} / \mathrm{s}\end{array}$ & $\begin{array}{c}\text { [22] } \\
\text { Yong Kang et. al. } \\
\text { using SIMS profiles }\end{array}$ \\
\hline $\begin{array}{c}\text { Au } \\
\text { diffusion }\end{array}$ & GaAs & & $\begin{array}{l}\text { Au atom } \\
\text { diffusivity }\end{array}$ & $\mathrm{D}=2.9 \times 10^{1} \exp (-2.64 / \mathrm{kT})$ & $\begin{array}{c}\text { [21] } \\
\text { D. Shaw }\end{array}$ \\
\hline As diffusion & GaAs & N/A & $\begin{array}{l}\text { As atom } \\
\text { diffusivity } \\
\left(\mathrm{V}_{\mathrm{As}}\right)\end{array}$ & $\begin{array}{c}\mathrm{D}\left(\mathrm{cm}^{2} / \mathrm{s}\right)=0.004 \exp \\
{[-1.8(\mathrm{eV}) / \mathrm{kT}]}\end{array}$ & $\begin{array}{l}{[25]} \\
\text { K.M.Lukenet.al. }\end{array}$ \\
\hline As diffusion & GaAs & $\begin{array}{c}1050 \\
850 \\
650\end{array}$ & $\begin{array}{l}\text { As vacancy } \\
\left(\mathrm{V}_{\text {As }}\right) \text { diffusion } \\
\text { coefficient }\end{array}$ & $\begin{array}{l}1.2 \times 10^{-12} \mathrm{~cm}^{2} / \mathrm{s} \\
5.8 \times 10^{-14} \mathrm{~cm}^{2} / \mathrm{s} \\
6.7 \times 10^{-16} \mathrm{~cm}^{2} / \mathrm{s}\end{array}$ & $\begin{array}{l}\text { [26] } \\
\text { V.Swaminathan, } \\
\text { et.al. }\end{array}$ \\
\hline
\end{tabular}

Our experimental results showed that the size of the SNCs depends strongly on the thickness of the Au catalyst island or the amount of Au catalyst: with thin Au island thickness $(<20 \mathrm{~nm})$ (Figure S1), the sizes of the Au droplets were small, the amount of $\mathrm{Ga}$ and As atoms diffusing into the Au droplets was very limited, the size of the SNCs was small, the vacancy accumulation for the formation of Kirkendall voids was very limited, and the chemical bonds between the SNCs and the GaAs substrate beneath the $\mathrm{Au}$ island were also strengthened. Consequently, this situation limited the outward 
diffusion of surface clusters, and the SNKE did not form. In contrast, with thicker Au catalyst islands (Au island thickness $>30 \mathrm{~nm}$ to $1000 \mathrm{~nm}$ ), a greater amount of $\mathrm{Ga}$ and As atoms diffused into the Au droplets, bigger sizes of SNCs were formed, and more vacancy accumulations led to the generation of Kirkendall voids. These situations resulted in weak chemical-physical bonds between the SNCs and the GaAs substrate beneath the Au islands. These facts strongly support the outward diffusion of SNCs to more easily form SNKE. Unfortunately, if the Surface Cluster (SCs) sizes are too large (in this case, these are not called SNCs) instead of the outwards diffusion from the Au catalyst island, the SCs create big voids inside the Au catalyst island, caused by the accumulation of many large Kirkendall voids [29].

\subsection{Numerical Estimation of SNC Diffusivity}

So far, the diffusivity data of surface clusters or SNCs cannot be found in the literature. Here, in order to estimate the diffusivity of SNCs, we used the Random Walk theory. In one direction, the diffusion coefficient can be estimated by the mean square displacement given by the Einstein relation, as follows $[15,20,21]$ :

$$
D \approx \frac{L^{2}}{t}, \text { or } L^{2} \approx D . t
$$

where $L$ is the diffusion length of SNCs, which is determined on the basis of experimental data from the FESEM micrograph, as shown in Figures $1 \mathrm{a}$ and 2a. The $t$ parameter is diffusion time; here, we chose the growing-diffusion time to be $t_{4}$. We used this relation in order to estimate the SNCs' diffusion coefficient, and our estimated values are listed in Table 2.

Table 2. The estimation of diffusivities of the surface $\mathrm{Au} / \mathrm{Ga} / \mathrm{O}$ clusters diffusion.

\begin{tabular}{ccccccccc}
\hline $\begin{array}{c}\text { Au /GaAs } \\
\text { Samples } \\
\text { Symbols }\end{array}$ & $\begin{array}{c}\text { Au islands } \\
\text { Thickness } \\
(\mathbf{n m})\end{array}$ & $\begin{array}{c}\mathbf{T}_{\mathbf{1}} \\
\left({ }^{\circ} \mathbf{C}\right)\end{array}$ & $\begin{array}{c}\mathbf{t}_{\mathbf{2}} \\
(\mathbf{m i n})\end{array}$ & $\begin{array}{c}\mathbf{T}_{\mathbf{2}} \\
\left({ }^{\circ} \mathbf{C}\right)\end{array}$ & $\begin{array}{c}\mathbf{t}_{\mathbf{4}} \\
(\mathbf{m i n})\end{array}$ & $\begin{array}{c}\text { Diffusion } \\
\text { Length, } \\
\mathbf{L}(\boldsymbol{\mu m})\end{array}$ & $\begin{array}{c}\text { Estimated } \\
\mathbf{D i f f u s i v i t y ,} \\
\mathbf{D} \sim \mathbf{L}^{\mathbf{2}} /\left(\mathbf{t}_{\mathbf{4}}\right) \\
\left(\mathbf{m}^{\mathbf{2}} / \mathbf{s}\right)\end{array}$ & $\begin{array}{c}\text { Figures } \\
\text { Concerning } \\
\text { Experiment } \\
\text { Data }\end{array}$ \\
\hline S9 & 1000 & 410 & 20 & 620 & 30 & $\sim 900$ & $4.50 \times 10^{-10}$ & Figure 1 \\
S10 & 1000 & 440 & 20 & 640 & 30 & $\sim 1300$ & $9.40 \times 10^{-10}$ & Figure 2 \\
S7 & 70 & 410 & 20 & 650 & 90 & $\sim 290$ & $1.567 \times 10^{-11}$ & Figure 3 \\
\hline
\end{tabular}

\subsection{On the Formation of the Nano Material Configurations Outside the Au Catalyst Island}

The formation mechanism of different kinds of nanomaterial configurations (NPs, NWs, and NRs) during the formation of SNKE is a hard problem to explain clearly. We could not find any previously published work reporting on this problem. In the work of T. Yoshiie et al. [19], where the the authors only investigated the interfacial reactions between polycrystalline thin films with an Au layer thickness of $30 \mathrm{~nm}$ and $60 \mathrm{~nm}$, and mono crystalline substrates of GaAs as a function of deposition temperature and subsequent annealing conditions in the range of $100{ }^{\circ} \mathrm{C}$ to $350{ }^{\circ} \mathrm{C}$ by transmission electron microscopy. Our study here is considerably different from the described work with respect to both the temperature range, which reaches up to above the Eutectic temperature, and the wider range of $\mathrm{Au}$ catalyst thickness from $20 \mathrm{~nm}$ up to $1000 \mathrm{~nm}$.

The growth mechanism could be briefly explained as follows: depending on the technological conditions (Au catalyst island/strip thickness, temperature profiles $\left(\mathrm{T}_{1}, \mathrm{~T}_{2}\right)$, and annealing times $\left(\mathrm{t}_{2}\right.$ and $\left.t_{4}\right)$ ), during the formation of SNCs inside the Au islands/strips, the dissolution of gallium atoms into $\mathrm{Au}$ droplets is able to reach to a supersaturated level or not. If the supersaturated level is not reached, the $\mathrm{Ga} / \mathrm{O}$ nucleations of the nano configuration seeds will not be formed completely, and the NWs are hard or cannot grow. With respect to the behavior SNCs as the NPs, during outwards diffusion, the SNCs maintain the form of NPs (as shown in Figure 1d). In contrast, if the supersaturated level is reached, the $\mathrm{Ga} / \mathrm{O}$ nucleations of the nano configuration seeds can be formed inside the SNCs, some nano configurations (NPs, NWs, NRs) also begin to form or grow (Figure S2b), and during the 
outward diffusion, the moving nano configurations (NPs, NWs and NRs) can receive the Ga and As atoms and the absorbed $\mathrm{O}$ atoms from the local places on the GaAs surface along the diffusion direction to grow more. Of course, if the supersaturated level is only partly reached, then the nanomaterial configurations (NPs, NWs, or NRs) will only be partly formed (Figure 2c,d).

On the basis of the obtained experimental results, depending on the technological conditions, different kinds of nano configurations (NPs, NWs, NRs) are grown in different forms (with weak bases and horizontally lying NWs (Figure 3, and Figures S4 and S5); with strong bases and vertically standing NWs (Figure 4c,d) with Au spheres located on the tips of NWs; and NPs and NRs with different forms). These results can support the following conclusion: the growth process of the nano material configurations here can be considered a typical case of the foreign Au catalyst element-mediated Oxide Assisted Growth (OAG) discussed in $[13,14]$; it cannot be considered to be the initial VLS method, growing purely by the VLS mechanism [7]. The growth mechanism of NPs, NWs and NRs can be explained by the vapor-solid-solid (vapor-solid) mechanism, whcih is actually a vapor-quasisolid-solid (vapor-quasiliquid-solid) mechanism, proposed in the works of S. Noor Mohammad et al. [12,14]. In reality, the formation and growth of NPs and NWs from the SNCs during the outward diffusion is a difficult problem to explain clearly. This kind of growth mechanism has not yet been reported in the literature, and should be studied in more detail.

\subsection{The Proposed Model of SNKE Formation}

Based on the obtained experimental results and the above discussions, we propose a draft model of SNKE formation, presented in Figure 6. This model outlines three main aspects, corresponding to three typical main periods:

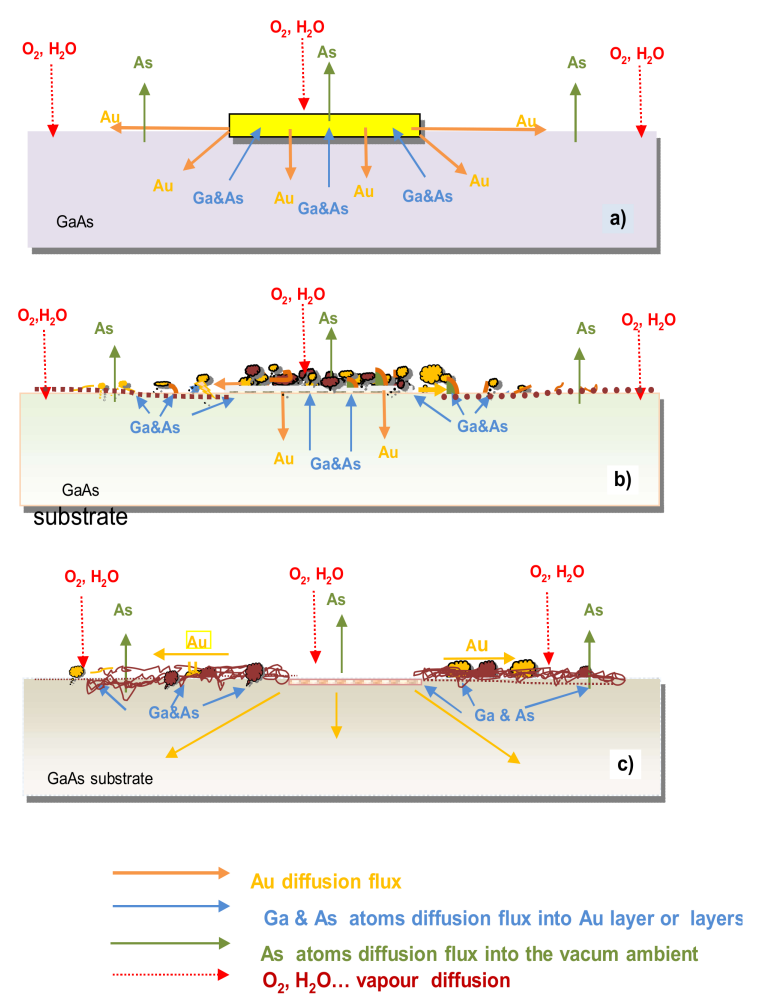

Figure 6. The proposed model demonstrating three typical main stages of SNKE formation caused by the outward diffusion of surface $\mathrm{Au} / \mathrm{Ga} / \mathrm{O}$ clusters. The first period is so-called beginning period (a) The second period is the decomposition process of $\mathrm{Au} / \mathrm{GaAs}$ and formation of the SNCs inside $\mathrm{Au}$ island (b), and the third period is the outwards diffusion of SNCs to form SNKE (c). 
Figure 6a shows the first period, the so-called beginning period. This mainly occurs during the time $t_{1}$ and part of time $t_{2}$. During this period, all of the diffusion fluxes of $\mathrm{Au}, \mathrm{Ga}, \mathrm{As}$, and of the remaining Oxygen $(\mathrm{O})$ and $\mathrm{H}_{2} \mathrm{O}$ vapors are starting to be set up and to occur. Here we suppose that the $\mathrm{Au}$ diffusion has two components: one Au diffusion component takes place inside the $\mathrm{Au}$ island along the GaAs substrate surface to form Au droplets, and the other Au diffusion component is diffused into the bulk of the GaAs substrate; this part does not participate directly in the formation of SNKE, and so we do not need to deal with it here. In addition, there are the diffusion fluxes of Ga, As atoms into the $\mathrm{Au}$ catalyst island, as well as into the Au droplets, and the diffusion flux (or absorbed flux) of Oxygen $(\mathrm{O})$ and $\mathrm{H}_{2} \mathrm{O}$ vapor into the $\mathrm{Au}$ droplets and the $\mathrm{GaAs}$ substrate; these atoms remain in the $10^{-1}$ pressure low vacuum closed quartz tube. The formation and diffusion of nanoscale objects (Au droplets, SNCs, Kirkendall voids) does not really take place during this period.

Figure $6 \mathrm{~b}$ shows a draft demonstration of the decomposition process of $\mathrm{Au} / \mathrm{GaAs}$ at temperature $\mathrm{T}_{1}$ during time $t_{2}$ and part of $t_{3}$. The Au metal catalyst island is disturbed into Au droplets. The GaAs material (Ga, As atoms) under the Au island dissolve readily into the Au island and gold-based alloys, i.e., the $\mathrm{Ga}$ and As atoms diffuse rapidly into Au droplets (their diffusivities can be seen in Table 1) to form SNCs. Many vacancy accumulation voids (Kirkendall voids) are generated just beneath the SNCs. The NKE are already formed, in addition to the $\mathrm{Ga} / \mathrm{O}$ nucleations (material nano seeds), either partly or completely for nanostructure growth depending on the level of supersaturation, as described above. The number of diffusion fluxes is the same as in the first period, but in this period, there are many physical-chemical reactions occurring, as discussed in Section 3.2, in order to form SNCs.

Figure $6 \mathrm{c}$ shows a draft demonstration of the complete formation of SNKE, where all SNCs diffused outward along the radial diffusion direction, leaving behind a bare GaAs hole in the place of the former location of the Au island, forming the so-called specific SKE. Kirkendall voids are also formed around the circumference of the bare GaAs hole, as shown in Figure 4a,b. During this period, an important diffusion flux predominates, which is the outward diffusion flux of SNCs from the Au island to form the SNKE; as a result of this, different nano configurations (NPs, NWs and NRs) were grown simultaneously, as shown in Figures 3 and 4.

\subsection{The Advantages and Disadvantages of SNKE and Applications}

(a) The advantages of SNKE

- The SNKE can be clearly observed directly on the semiconductor substrate surface; meanwhile, the NKE are formed in hollow nanotubes and hollow nanospheres, where their phenomena are hard to observe directly.

- The SNKE can be controlled by changing the temperature profile and annealing-growing times, and especially by changing the thickness of the Au metal catalyst island (Au amount). We could control the degree of formation of SNKE with several options, as follows:

- We can grow the NWs normally with the traditional VLS method without SNKE if the thickness of the Au metal catalyst island is smaller than $20 \mathrm{~nm}$.

- We can produce the SNKE with primarily growth of NPs only if we choose a moderately low $\mathrm{Au}$ island thickness in the range of $35 \mathrm{~nm}$ to $100 \mathrm{~nm}$, a low $\mathrm{T}_{1}$ decomposition temperature $\left(410{ }^{\circ} \mathrm{C}\right), \mathrm{a} \mathrm{T}_{2}\left(610-620^{\circ} \mathrm{C}\right)$ temperature that is lower than the Eutectic temperature $\left(630^{\circ} \mathrm{C}\right)$.

- We can produce the SNKE with primarily growth of NWs if we choose a moderately low $\mathrm{Au}$ island thickness in the range of $35 \mathrm{~nm}$ to $100 \mathrm{~nm}$, a low $\mathrm{T}_{1}$ decomposition temperature $\left(410^{\circ} \mathrm{C}\right)$ and $a \mathrm{~T}_{2}\left(610-620^{\circ} \mathrm{C}\right)$ temperature lower than the Eutectic temperature $\left(630^{\circ} \mathrm{C}\right)$.

- We can produce SNKE with the growth of mixed configurations of nanomaterials (NPs, NWs, NRs) if we choose a thick Au metal catalyst thickness (>200-1000 nm) and high temperature modes $\left(\mathrm{T}_{1}=440^{\circ} \mathrm{C}\right.$ and, $\left.\mathrm{T}_{2}=640^{\circ} \mathrm{C}\right)$. 
- We can produce SNKE with the growth of NWs with strong or weak bases on the GaAs substrate if we choose a moderate $\mathrm{T}_{1}$ temperature $\left(400-410^{\circ} \mathrm{C}\right)$ and a $\mathrm{T}_{2}$ temperature higher than the Eutectic temperature $\left(630^{\circ} \mathrm{C}\right)$ with a long growing-diffusion time $\mathrm{t}_{4}$.

(b) The disadvantages of SNKE

- $\quad$ During the fabrication of a micro nano integrated circuit on the $\mathrm{A}^{\mathrm{III}} \mathrm{B}^{\mathrm{V}}$ substrate material, the $\mathrm{Au}$ strips/islands are often evaporated (or sputtered) onto the semiconductor substrate surface; this is followed by a thermal annealing process in a moderately high temperature range from 200 to $400{ }^{\circ} \mathrm{C}$ in order to produce a metal contact system on the semiconductor surface. If we do not take care of the technological process, the disadvantages of SNKE could predominate: the outward diffusion to further distances from the $\mathrm{Au}$ islands and/or Au strips, which could cause short circuit faults in nano devices or in micro- and nanoscale integrated circuits. We think that a similar effect could also occur for strips/islands of other metals ( $\mathrm{Ni}, \mathrm{Fe}, \mathrm{Ag}$, Al, etc.) on semiconductors $(\mathrm{Si}, \mathrm{InSb}, \mathrm{Ge}$, etc.) used as interconnection contacts.

- The formation of SNKE could result in tissue loss due to uneven surfaces, local defects, and hole and pit etchings; these could generate several problems on semiconductor surfaces that contain micro and nano devices or integrated circuits, causing the loss in the form of current leakage and other effects.

\section{Materials and Methods}

Our experiments here are focused on investigating the formation of the SNKE, so the technological processes are somewhat different from the experimental procedures used in previous works $[8,9]$. The starting materials were n-type GaAs slices with (100) orientation. In the first step, the GaAs slice was chemically treated by immersing it in a solution of deionized water (DI): $\mathrm{HCl}$ with a volume ratio of 3:1 and removing the $\mathrm{HCl}$ with acetone and alcohol over 5-10 min, followed by ultrasonic vibrating in the ionized water and drying. After that, the slice was cleaned by ultrasound vibration in three solutions successively: acetone solution $\left(\mathrm{CH}_{3} \mathrm{COCH}_{3} 99.5 \%\right)$; alcohol solution $\left(\mathrm{CH}_{3} \mathrm{CH}_{2} \mathrm{OH} 95 \%\right)$; and ionized water; followed by drying. In the second step, different $\mathrm{Au}$ island/strip thicknesses from $20 \mathrm{~nm}$ to $1000 \mathrm{~nm}$ were sputtered through a stencil mask onto the surface of the GaAs substrate in order to produce Au islands/strips/GaAs configurations as shown in Figure 7a. After that, the GaAs slice was cut into small samples (Figure 7a, and the samples were then treated chemically for cleaning and drying. After this step, the small-cut sample was placed on a quartz boat that was placed into a $10^{-1}-10^{-2}$ low vacuum closed tube. A three-zone GSL1600X furnace was used (Figure 7d) and heated in accordance with the desired two-step temperature profile (Figure 7e) with an automatic temperature control process. The temperature profile was measured automatically at a point close to the sample located inside the closed tube using the thermal couple connected with a PC via a Keithley2000 multimeters as shown in Figure 7f. The low vacuum value in the closed tube was maintained by the pump and measured constantly throughout the whole technological process. The technological process was repeated for each experimental sample. Here, it is worth noting that the thermal VLS method was used with a two-step temperature profile with $\mathrm{Au} / \mathrm{GaAs}$ decomposition temperatures $\left(\mathrm{T}_{1}\right)$ chosen in the range of $410{ }^{\circ} \mathrm{C}$ to $440{ }^{\circ} \mathrm{C}$ with an annealing time $\left(t_{2}\right)$ of $20 \mathrm{~min}$, diffusion-growing temperature $\left(\mathrm{T}_{2}\right)$ of $610^{\circ} \mathrm{C}$ to $650^{\circ} \mathrm{C}$ around the Eutectic temperature $\left(630^{\circ} \mathrm{C}\right)$ of the $\mathrm{Au} / \mathrm{GaAs}$ system with the diffusion-growing time $\left(t_{4}\right)$ in the range of $30 \mathrm{~min}$ to $90 \mathrm{~min}$. After performing the experiments, the samples were investigated by the Alpha-Step IQ equipment, the FESEM technique on the FESEM-Hitachi S-4800 equipment, and the energy-dispersive X-ray (EDX) technique. Here, we were not able to successfully carry out the TEM and HRTEM investigations due to limitations in our samples preparations. 

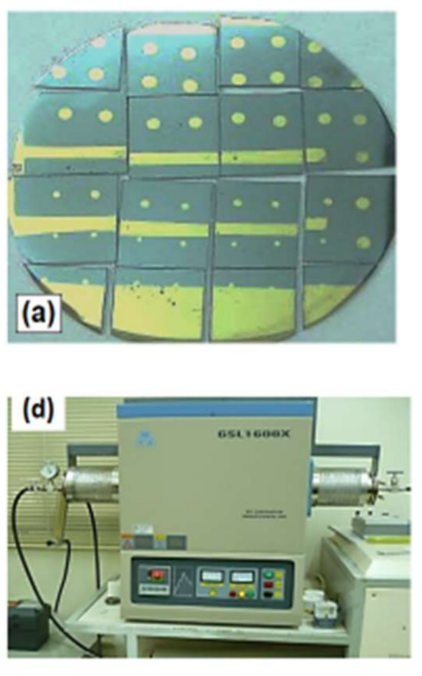

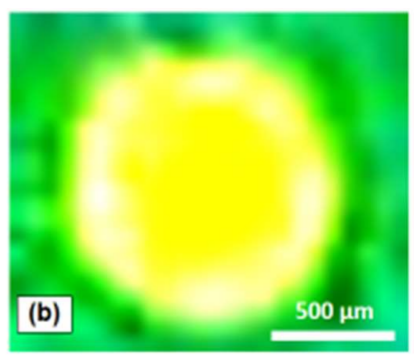

(e)

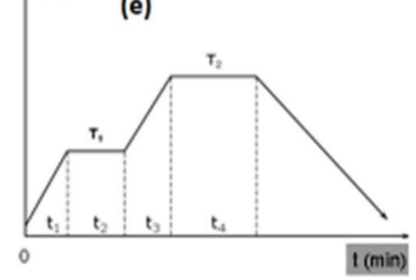

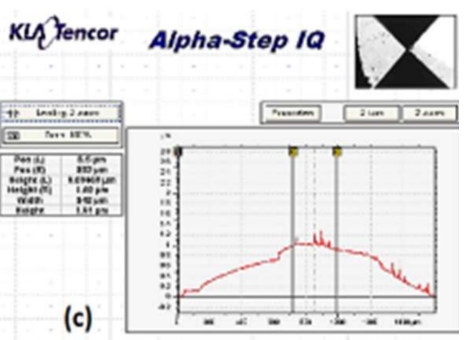

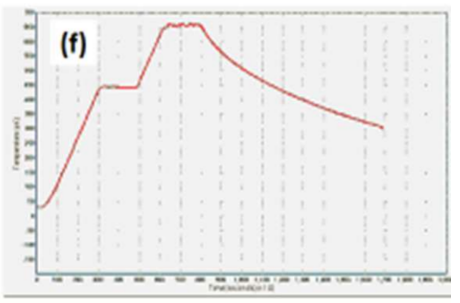

Figure 7. Photographs of $\mathrm{Au}$ islands/GaAs substrate slice with the cut small samples (a); The magnification photograph of an initial Au circle island (b); the measured result of $\mathrm{Au}$ island thickness of $1000 \mu \mathrm{m}$ by Alpha-Step IQ equipment, as an example (c); photograph of the $10^{-1} 10^{-2}$ torr low vacuum closed tube furnace (d), the demonstrated scheme of the thermal VLS method with two-step $\left(\mathrm{T}_{1}, \mathrm{~T}_{2}\right)$ temperature mode $(\mathbf{e})$, and the two-step temperature profile measured and identified by PC using a thermal couple connected with Keithley2000 multimeters, as an example (f).

\section{Main Conclusions}

The so-called SNKE is outlined and discussed here for the first time in detail based on experimental results.

The SNKE formed based on the combination of two specific kinds of Kirkendall effects: the specific NKE formed during the formation of SNCs leaving behind vacancy voids just the beneath the SNCs, and the specific SKE formed during the outward diffusion of SNCs leaving behind a bare GaAs hole in place of the former location of the Au catalyst island. SNKE formation depends strongly on technological conditions.

SNKE is an important part of KE for applications in the fabrication of nanomaterial configurations (NPs, NWs and NRs) on semiconductor surfaces.

SNKE formation can be controlled through the technological conditions, including Au metal catalyst thickness, the thermal VLS method with a two-step $\left(\mathrm{T}_{1}, \mathrm{~T}_{2}\right)$ temperature mode, and thermal annealing times $\left(t_{2}, t_{4}\right)$.

With the technological process carried out at thin Au island/strip thicknesses $(<20 \mathrm{~nm})$, NWs with small sizes could be grown rapidly by the VLS growth mechanism. There was free of outward diffusion and SNKE. With the technological process carried out at thicker Au island/strip thicknesses (from $30 \mathrm{~nm}$ to $1000 \mathrm{~nm}$ ) in the $10^{-1} 10^{-2}$ torr low vacuum closed tube, the SNKE could be formed partly or completely with different grades, depending on the thermal annealing VLS temperature profiles and annealing times.

The essential mechanism determining the SNKE is the diffusion of the elemental Au Ga, As, and $\mathrm{O}$ atoms into the Au droplets, forming the SNC and Kirkendall void nanoscale objects. The SNCs diffused outwards as a result of the formation of a diffusion force by the concentration gradient of the clusters, and the weak chemical-mechanical bonds between the SNCs and the GaAs substrate due to the porosity, Kirkendall voids, and pit-etching beneath the Au island.

The diffusion of the elements $\mathrm{Au}, \mathrm{Ga}$, As were discussed, and their diffusivities were outlined for purposes of comparison. The diffusivity of the surface $\mathrm{Au} / \mathrm{Ga} / \mathrm{O}$ clusters was estimated for the first time, with their values being in the range of $8.00 \times 10^{-12}$ to $6.72 \times 10^{-10} \mathrm{~m}^{2} / \mathrm{s}$, depending on the technological conditions. 
The SNKE has the following advantages: it is possible to use and control this kind of technological process for the directional growth of different morphologies of NPs, NWs and NRs along the radial diffusion direction on the GaAs surface for building nanostructured devices blocks. However, the SNKE also has disadvantages: it could cause short circuit faults in nano devices and micro and nano integrated circuits. The SNKE could also cause tissue loss, local surface defects, and hole pit etching, and this could cause some problems and other effects in micro and nano devices and integrated circuits.

Supplementary Materials: The following are available online at http://www.mdpi.com/2073-4344/9/12/1072/s1, Figure S1: The SNKE was not formed at the thin Au catalyst island $(<20 \mathrm{~nm})$ between two Au catalyst islands (b) on the sample S1, the NWs have grown regularly by thermal VLS method, Figure S2: SEM micrographs of surface nanoscale $\mathrm{Au} / \mathrm{Ga} / \mathrm{O}$ clusters (SNCs) formed inside the Au catalyst island on Sample S2. The SNCs have the sizes of from $30 \mathrm{~nm}$ to about $100 \mathrm{~nm}(\mathrm{~b}, \mathrm{c}, \mathrm{d})$. Several NWs are began to grow (b), Figure S3:The different magnified SEM micrographs of the different corners of the bare GaAs hole formed on the place of the former Au catalyst island on the sample S6, where SNKEc ompletely formed, simultaneously the mixed nanomaterials (NPs,NWs,NRs) have grown on GaAs surface along the radius direction (arrowsdirection), Figure S4: The different magnified SEM micrographs of NWs with the weaken bases and big tips (spheres) on Sample S3 that are diffused outward and grown, Figure S5: The different magnified SEM micrographs of NWs grown on the outside of Au catalyst island/strip on Sample S5 with weaken bases and big tips (spheres) located on the NWs tops, Figure S6: Several SEM micrographs on the Sample S10 more in detail concerning Figure 2, Table S1. The symbols of several typical samples and technological conditions using in the experiments by the VLS method with two steps temperature mode in the $10^{-1}-10^{-2}$ torr low vacuum closed tube for investigation of the SNKE formation on Au island/GaAs substrate.

Author Contributions: Conceptualization, K.A.D.; Formal analysis, K.A.D.; Investigation, H.T.P., T.T.N. and A.T.P.; Methodology, K.A.D.; Resources, H.T.P. and A.T.P.; Writing一original draft, K.A.D.

Funding: This study was funded by the National Foundation of Science and Technology Development (NAFOSTED) for the basic research project (103.02.-2017.346) in the 2018-2021 period.

Acknowledgments: We also express many thanks to Assoc. Hung Manh Do and Van Vuong Hoang for the SEM, TEM measurements and discussions.

Conflicts of Interest: The authors declare that they have no conflict of interest.

\section{References}

1. Kirkendall, E.; Thomassen, L.; Upthegrove, C. Rates of Diffusion of Copper and Zinc in Alpha Brass. Trans. AIME 1939, 133, 186-203.

2. Kirkendall, E.O. Diffusion of Zinc in Alpha Brass. Trans. AIME 1942, 147, 104-110.

3. Tu, K.N.; Gösele, U. Hollow nanostructures based on the Kirkendall effect: Design and stability considerations. Appl. Phys. Lett. 2005, 86, 093111. [CrossRef]

4. Fan, H.J.; Gösele, U.; Zacharias, M. Formation of Nanotubes and Hollow Nanoparticles Based on Kirkendall and Diffusion Processes: A Review. Small 2007, 3, 1660-1671. [CrossRef]

5. Prasad, S.; Paula, A. Theoretical consideration on the formation of nanotube following the Kirkendall effect. Appl. Phys. Lett. 2007, 90, 233114. [CrossRef]

6. Wang, W.; Dahl, M.; Yin, Y. Hollow Nanocrystals through the Nanoscale Kirkendall Effect. Chem. Mater. 2013, 25, 1179-1189. [CrossRef]

7. Wagner, R.S.; Ellis, W.C. Vapor-liquid-solid mechanism of single crystal growth. Appl. Phys. Lett. 1964, 4, 89. [CrossRef]

8. An, D.K.; Chung, N.X.; Trang, P.H.; van Vuong, H.; Phong, P.V.; Tuan, P.A. On growth mechanisms and dynamic simulation of growth process based on the experimental results of nanowire growth by VLS method on semiconductor substrates. J. Phys. Conf. Ser. 2009, 187, 1. [CrossRef]

9. Dao, K.A.; Phan, A.T.; Do, H.M.; Luu, T.H.; Falke, M.; MacKenzie, M. The influences of technological conditions and $\mathrm{Au}$ cluster islands on morphology of $\mathrm{Ga}_{2} \mathrm{O}_{3}$ nanowires grown by VLS method on GaAs substrate. J. Mater. Sci. Mater. Electron. 2011, 22, 204-216. [CrossRef]

10. Yin, Y.; Rioux, R.M.; Erdonmez, C.K.; Hughes, S.; Somorjai, G.A.; Alivisatos, A.P. Formation of Hollow Nanocrystals Through the Nanoscale Kirkendall Effect. Science 2004, 304, 711-714. [CrossRef]

11. El Mel, A.B.; Nakamura, R.; Bittencourt, C. The Kirkendall effect and nanoscience: Hollow nanospheres and nanotubes. Beilstein J. Nanotechnol. 2015, 6, 1348-1361. Available online: https://www.beilstein-journals.org/ bjnano/articles/6/139 (accessed on 20 September 2019). [CrossRef] [PubMed] 
12. Mohammad, S.N. For nanowire growth, vapor-solid-solid (vapor-solid) mechanism is actually vapor-quasisolid-solid (vapor-quasiliquid-solid) mechanism. J. Chem. Phys. 2009, 131, 224702. [CrossRef] [PubMed]

13. Zheng, Y.F.; Tang, Y.-H.; Wang, N.; Yu, D.P.; Lee, C.S.; Bello, I.; Lee, S.T. Silicon nanowires prepared by laser ablation at high temperature. Appl. Phys. Lett. 1998, 72, 1835. [CrossRef]

14. Mohammad, N.S. Investigation of the oxide-assisted growth mechanism for nanowire growth and a model for this mechanism. J. Vac. Sci. Technol. B Microelectron. Nanom. Struct. 2008, 26, 1993-2007.

15. Surface Diffusion-Wikipedia. Available online: http://en.wikipedia.org/wiki/surface_diffusion (accessed on 20 September 2019).

16. Weizer, V.G.; Fatemi, N.S. The interaction of gold with gallium arsenide. J. Appl. Phys. 1988, $64,4618$. [CrossRef]

17. Liliental-Weber, Z.; Washburn, J.; Newman, N.; Spicer, W.E.; Weber, E.R. Morphology of Au/GaAs interfaces. Appl. Phys. Lett. 1986, 49, 1514.

18. Akiyama, O.T.; Haneda, Y.; Nakamura, K.; Ito, T. Role of Au/GaAs (111) interface on the wurtzite-structure formation during GaAs nanowire growth by vapor-liquid-solid mechanism. Phys. Rev. 2009, 79, 153406. [CrossRef]

19. Yoshiie, T.; Bauer, C.L.; Milnes, A.G. Interfacial reactions between gold thin films and GaAs substrates. Thin Solid Films 1984, 111, 149-166. [CrossRef]

20. Chen, B.; Fu, X.; Tang, J.; Lysevych, M.; Tan, H.H.; Jagadish, C.; Zewail, A.H. Dynamics and control of gold-ncapped gallium arsenide nanowires imaged by 4D electron microscopy. PNAS 2017, 114, 12876-12881. [CrossRef]

21. Shaw, D. Atomic Diffusion in Semiconductors; Plenum: New York, NY, USA, 1973.

22. Kang, Y.; Li, X.; Gong, H.; Jiang, R. Semicond. Sci. Technol. 2003, 18, 607-610.

23. Fisher, D.J. Diffusion in GaAs and Other III-V Semiconductors; SCITEC Publications; Volume 157-159, Available online: http://www.pearton.mse.ufl.edu/semicproperties/data/5032.pdf (accessed on 17 May 2019).

24. Tan, T.Y. Point defects and diffusion mechanisms pertinent to the Ga sublattice of GaAs. Mater. Chem. Phys. 1995, 40, 245-252. [CrossRef]

25. Luken, K.M.; Morrow, R.A. Diffusing arsenic vacancies and their interaction with the native defect EL2 in GaAs. J. Appl. Phys. 1996, 79, 1388-1390. [CrossRef]

26. Swaminathan, V.; Caruso, R.; Pearton, S.J. Photoluminescence from annealed semi-insulating GaAs crystals: The 1.360-eV band. J. Appl. Phys. 1988, 63, 2164-2167. [CrossRef]

27. Gösele, U.; Tan, T.Y.; Schultz, M.; Egger, U.; Werner, P.; Scholz, R.; Breitenstein, O. Diffusion in GaAs and Related Compouds: Recent developments. Defect Diffus. Forum 1997, 143-147, 1079-1094. [CrossRef]

28. Seebauer, E.G.; Allen, C.E. Estimating surface diffusion coefficients. Prog. Surf. Sci. 1995, 49, $265-330$. [CrossRef]

29. Dao, K.A.; Nguyen, T.D.; Phan, A.T.; Do, H.M. On the formation of voids, etched holes, and GaO particles configuration during the nanowires growth by VLS method on GaAs substrate. J. Mater. Sci. Mater. Electron. 2013, 24, 2513-2520. [CrossRef]

(C) 2019 by the authors. Licensee MDPI, Basel, Switzerland. This article is an open access article distributed under the terms and conditions of the Creative Commons Attribution (CC BY) license (http://creativecommons.org/licenses/by/4.0/). 